$\$$ Research Square
Preprints are preliminary reports that have not undergone peer review.

They should not be considered conclusive, used to inform clinical practice, or referenced by the media as validated information.

\title{
Missed Nursing Care: Concept Analysis Using the Hybrid Model
}

\section{Shoeleh Rahimi}

University of Social Welfare and Rehabilitation Sciences.Tehran,Iran

\section{Hamid Reza Khankeh ( $\sim$ Khankeh1964@yahoo.com )}

Health in Emergency and Disaster research center, University of Social Welfare and Rehabilitation Sciences, Tehran, Iran.Department of Clinical Science and Education, Karolinska Institute, Stockholm, Sweden

\section{Azam Sharifi \\ Hamedan University of Medical Sciences \\ Batol Mohammadian \\ Gonabad University of Medical Sciences}

\section{Research Article}

Keywords: Missed nursing care, Concept Analysis, Hybrid Model

Posted Date: January 4th, 2021

DOI: https://doi.org/10.21203/rs.3.rs-136175/v1

License: (c) (i) This work is licensed under a Creative Commons Attribution 4.0 International License.

Read Full License 


\section{Abstract}

Background and Objectives: Miss care is a quality index, which has been identified for nursing care and patient safety recently. However, no precise definition is available for the clinical dimensions and features of this concept. Thus, the present study aimed to analyze the concept of miss nursing care based on the hybrid model.

Design: A concept analysis was conducted using a three-phase(theoretical phase, fieldwork phase and final analysis phase) hybrid method.

Methods:In the theoretical phase, the concept of miss care was explored in reliable databases from 1998 up to 2018. Using COREQ guidelines, in the field work phase, in-depth interviews were conducted with six nurses and the data were analyzed using content analysis method. In the last phase, the final analysis was carried out.

Results: The results indicated miss care as a healthcare error as a kind of negligence in which the nurse provides unmanaged patient care due to the adversity of organizational and process background factors, which results in the negligence of essential cares and leads to consequences for both the patient and the nurse.

Conclusion: Based on the present concept analysis, unmanaged care was the main feature of miss care, which had not been included in the previous definitions. Nurses can create an accurate structure for nursing care and reduction of miss care through performance of process-based care and determination of nursing care priorities. Further studies are recommended to compare this concept to similar ones to determine the clinical distinctions.

\section{Introduction}

The quality of nursing services is a major factor in patient safety. Patient safety in healthcare centers requires continuous quality promotion (1). This concept is dependent on nursing performance and is affected by errors in any aspect of patient care (2). Thus, assurance of patient safety and nursing care quality is an important challenge for nursing managers. In order to intervene in the methods for increasing safety and care quality, nursing managers should first understand the opportunities that improve care as well as the barriers against care provision (3).

One of the objectives of patients' rights charter is assurance of the health system's responsiveness to patient needs. However, lack of time and personnel could lead to the ignorance of key points in patient care (4). In other words, patients' numerous care demands in a healthcare environment with lack of resources may cause nurses to prioritize the demands (5). Under such circumstances, the nurse decides which responsibilities to carry out or ignore (4). Consequently, some nursing responsibilities are missed (5). The neglected responsibilities may be different depending on various reasons, such as pressure for prioritization, teamwork, and the nurse's internal value system (6). However, what occurs during nursing 
care provision has not been well identified. In other words, the specific outcomes of what nurses do or do not have not been well determined. In this context, negative outcomes seem to be associated to what Kalisch has called miss care (7).

Miss care is a quality index identified for nursing care and patient safety recently (8). This concept encompasses all dimensions of clinical, emotional, and prescriptive nursing care that have not been completed or have been delayed (9). It has also been defined as the arbitrary omission of care, long delay in health services provision, and irrecoverable measures(10). Hence, miss care refers to inaccurate performance of healthcare. In this regard, safety specialist James Reyes believes that miss care is a common reason for the problems that can affect the quality of care and lead to the incidence of undesirable outcomes for patients (11). Evidence has revealed that miss nursing care or cares that have not been completed or have been postponed to the next shift are quite usual (12). In developed countries, it has been estimated that one out of every ten hospitalized patients is hurt due to care negligence (7). In this regard, a previous study demonstrated that miss nursing care was quite usual in U.S. hospitals. In that study, nearly three-fourths of nurses reported at least one miss care during their last shift. This measure has been found to be greatly higher in developing countries, such a way that all nurses reported the incidence of miss care in some hospitals (13). In a study conducted by Matin et al, on the reporting of nursing errors in Iran between 2000 and 2017, It was found that the prevalence of nursing errors in different regions of Iran is different and is between 17 and $88 \%$, which is an average of $53 \%$ of the total number of nursing errors.

Overall, this concept is highly important and is associated with nurses' performances and patients' outcomesThus, it requires a comprehensive and acceptable theoretical definition, so that professional health team members will be able to measure the experimental features of the concept in order assess its impacts on quality, patient safety, and nurses' work environment. Although miss nursing care occurs frequently, it has not been defined comprehensively and has not been recognized as an important phenomenon in nursing. Thus, the reasons why this concept has been less taken into consideration have to be explored. In order to investigate the concept, it should be determined what missed care refers to and how it is differentiated from the related concepts (5) also miss care is a context bond concept and should be examined with a focus on the context and context surrounding the concept. Concept analysis is a major technique in development of nursing knowledge (14). Some researchers also believe that concept analysis is of particular importance in development of nursing knowledge and theories (15). Indeed, many nursing theories have been created based on such concepts. Therefore, concept analysis has been supported as an important approach in development of nursing knowledge. Miss nursing care is a phenomenon that is frequently reported in nursing services, but it has been described using various terms with no precise boundaries such as implicitly rationed care, nursing care left undone, unmet patient needs, unfinished nursing care, and delayed nursing care. Additionally, it has been assumed that miss nursing care might be directly associated with nurse and patient outcomes (16). Hence, increased recognition of this phenomenon can increase the understanding of its relationship with patient care quality (17). The present study aims to answer the following questions: What is miss care? Why does it occur? How do nurses experience miss care? What are its consequences for patients and nurses? In this 
context, various approaches have been employed by researchers for development of the concept. Concept analysis has been considered to be a strategy for development of the concept as well as its basic elements with the aim of determining its nature and function.

\section{Aims and objectives}

The present study aims to analyze the concept of miss care based on literature review and experimental observations so as to make the concept applicable in clinical environments in Iran's healthcare system. The findings can enhance healthcare specialists' perception of the characteristcs, definitions, features, causes, and outcomes of miss care.

\section{Methods}

\section{Hybrid method}

The hybrid model helps clarify, identify, analyze, and modify concepts in the primary stages of development of a theory. This model is mostly utilized in nursing (18). The hybrid model is a combination of deductive and inductive approaches and aims at identification of the basic properties of a concept and clarify presentation of the concept based on the participants' experiences of observations and interviews(19). In other words, such components as previous studies, field work, and their combination can help clarify the concept. This model is composed of three stages, namely theoretical phase, field work phase (semi-structured interviews with nurses), and final analytical phase (integration of the results of the two previous stages). The theoretical phase helps progress and deeply analyze the concept in the following stages. The field work phase is performed simultaneously with the first phase. In this step, qualitative data collection helps emphasize the experimental component of the process so as to empower the primary concept. Finally, the last stage aims at integrating the results of theoretical analysis and those obtained from experimental observations and reporting the final findings (20). In this way, the concept is clarified and novel concepts, which are sometimes completely different from the primary ones, will be revealed (19).

\section{Theoretical phase}

In this stage, search was conducted in reliable databases, including Science Direct, Google Scholar, Scopus, Prequest, and Pubmed. A search was conducted using the Mesh terms keywords:

"implicitly","Nursing Care","Delay”. Review of the related articles was done in a 20-year period from 2004 to 2018. Totally, 182 English and articles were found 29 of which met the inclusion criteria of the research(Figure 1). The inclusion criteria were existence of keywords in the article, relatedness to the concept, availability of the full text, and not being repeated. This stage aimed at redefinition of the concept and presentation of a working definition to be used in the field work phase.

\section{Field work phase}


This phase aimed at empowerment of the concept formed in the previous phase using experimental observations. Since this clinical concept has no boundaries for healthcare service providers, particularly nurses, the field work phase was begun with clinical data collection in a hospital affiliated to Shiraz University of Medical Sciences. In the hybrid model, the thoroughness of interviews is more important than the number of interviews and often 3-6 interviews are deemed sufficient(19). To ensure the accuracy of data, the interviews were continued until data saturation, i.e., the data became repetitive.

After gaining a relatively comprehensive viewpoint towards miss care in the theoretical phase, the participants were selected based on purposeful sampling from the experienced individuals who provided nursing care in various wards. The participants were selected from the various wards (Intensive Care Unit [ICU] and the internal, surgery wards) of university hospitals in the city of shiraz, Iran. In this way, six clinical nurses were selected with the mean age of 33 years (ranging from 28 to 39 years). Five out of the six nurses were single and female and had B.Sc. degrees. The interviews lasted for 20-30 minutes. The contents of the interviews were digitally recorded and used as the main data of the research. Data collection was conducted between 3 October 2018-5 November 2018.

The procedures were explained in detail,including the fact that interviews would be audio-recorded. After obtaining oral and written consent, face-to-face interviews were conducted with the participants. To protect the privacy of the participants, numerical codes were used instead of their names and any identifying information was removed from the transcripts. We tried to hold the interviews in a private room in the wards where the nurses worked, which is the natural environment for the phenomenon in question. All written reports were kept in a safe place and made available only to the researchers working on the project.

The interviews were performed individually using open-ended and semi-structured questions. These questions were designed while reviewing the literature. The first question was "Based on your experiences, what kind of cares do you provide for patients during a work shift". The following questions dealt with miss care and included "At the time of patient care, what aspects of nursing care have you neglected or delayed?", "How did you experience it?", "What are the barriers against the provision of complete patient care?", and "What are the consequences for patients and nurses?". After listening to the interviews, the all data were transcribed and the data were analysied using a conventional qualitative content analysis approach and explored codes were classified into categories. It should be noted that the participants were reassured about their freedom to take part in the interviews and the research.

Confidentiality of the participants' information was observed, as well. Furthermore, trustworthiness of the research were ascertained via the researcher's prolonged engagement with the participants, better

understanding of the environment, and review of the data by the second researcher(peer check) and result and research process checked with research team(expert check).

\section{Final phase}

This phase involved integration of the two previous stages and explored characteristics in the theoretical and filed work phases. Afterwards, the characteristics were compared, and an comprehensive definition 
of the concept was provided.

\section{Ethical considerations}

This study was approved by the Ethics Committee of University of Social Welfare and Rehabilitation Sciences(uswr).Tehran,Iran. all methods were performed in accordance with the relevant guidelines and regulations. All the participants were informed of the aim of the study and a written consent was obtained from each of them. Participation in the study was entirely voluntary and the participants could withdraw at any stage of the study. Confidentiality of the data was also taken into consideration and the results were published anonymously.

\section{Results}

\section{Review of literature: Theoretical phase}

Miss nursing care was first identified by Kalisch (2006) in a qualitative investigation(21). That study was conducted using five focus group discussions with nurses, nursing assistants, and secretaries in two hospitals. The results revealed nine frequently neglected nursing cares (assisting a patient to walk, Change position, delay in feeding or not feeding patients, training patients, planning for discharge, emotional support, oral hygiene, recording fluids entry and exit, and supervision) and seven themes about the reasons for negligence of these cares (shortage of staff, weak utilization of the staff resources, time required for nursing interventions, weak team work, inefficient delegation of authority, habits, and denial) (7).

Since missed nursing care a key measure for patient safety, a clear definition of missed care is required in order to determine what kind of care is neglected and how it is differentiated from the related concepts. Although miss nursing care occurs frequently, it has not been identified as an important nursing phenomenon.

\section{Characteristics and definition of missed nursing care}

Miss nursing care has been referred to as restricted nursing care, nursing care left undone, unmet patient needs, unfinished nursing care, and delayed nursing care. This concept points to essential nursing cares that have been delayed or any clinical, emotional, or prescriptive dimension of cares that have been forgotten for any reason (1). In the research conducted by Kalisch (2006) to analyze the concept of miss care using Walker and Avant's approach, this concept was defined as any dimension of patient care neglected or considerably delayed by nursing staff due to frequent demands and insufficient resources (22). It has also been defined as an element of nursing care that has not been performed completely rather than a nursing care carried out incorrectly (23). Another study defined the concept as the intentional omission of care, long delay in care services provision, and irrecoverable measures (10). Indeed, the concept of rationed nursing care, which may be substituted with miss care, has been defined as not performing the necessary nursing responsibilities due to shortage of nursing resources (lack of 
time, staff, and combination of skills). In other words, a healthcare provider may ignore some nursing activities because of being faced with limited resources (24). Rationed nursing care occurs during the nurse's relationship with the patient based on the nurse's evaluations and results from her/his clinical judgement and decision-making (25). Organizational and social grounds are also effective in the incidence of rationed nursing care (26). In a previous study, delayed nursing care was defined as a combination of miss nursing care and rationed nursing care. This concept is used to describe a care that has not been carried out by the nurse and has been postponed to the next work shift (12). Experimentally, Sochalski (2004) defined unfinished care as some nursing responsibilities that had not been completed by the nurse in the previous shift (27). Review of the literature revealed no other definitions for miss nursing care. Moreover, most studies had explored the reasons for miss care, specific aspects of nursing care that had been neglected, and their consequences. These studies mostly dealt with the effective factors in miss care (28), postoperative mortality (29), urinary tract infection (30), hospital-acquired pneumonia (31) and patient falls (32), while less attention was paid to the concept of miss care. Besides, this concept has been usually evaluated using the Miss Care Survey, which contains two parts (nursing care elements and reasons for miss care) (3).

\section{Attribute}

More accurate investigation of the articles indicated that the concept of miss care had the following attribute:

Act of omission: This phrase has been referred to as a great error by the Patient Safety Commission and describes a dimension of nursing care that has been neglected, while it is expected to be done scientifically and technically. This error can have a considerable impact on the quality of care, patient safety, and nursing function (e.g., assisting a patient to walk). This type of error is more common and at the same time more serious. In fact, it focuses on the negligence errors that result in miss nursing care (33) and may occur in three forms as follows:

1) Not performing the essential nursing care for patients: Miss nursing care refers to the essential nursing cares in any clinical, emotional, and executive dimensions, which have not been carried out for any reason (1). It should be mentioned that essential nursing cares are determined based on nursing judgement, provider's prescriptions, or professional standards (34). Some elements of nursing care that require more time and involvement tend to be neglected more. The most frequent miss cares have been reported to be primary care services, such as assisting the patient to walk, changing the patient's position, oral hygiene, timely feeding the patient, providing emotional support for the patient and his/her family, training the patient, timely prescription of medications, documentation, and participation in interdisciplinary conferences, irrespective of situation and country (8).

2) Unfinished nursing care: Unfinished nursing care is a different kind of underuse and a growing concern in healthcare at the international level. Underuse occurs when healthcare services that are accompanied with desirable outcomes for patients are not fulfilled(33). This may include evaluation of patients, development of care plans, and provision of nursing cares required for patient care (35). Overall, 
unfinished care has been conceptualized as a three-dimensional phenomenon, including a problem (lack of time or resources), a process (clinical decision-making for prioritization and rationed care), and an outcome (care left undone) (33).

3) Delayed nursing care: Delayed care has been defined as miss care or rationed care. Various forms of delayed care depend on the accessibility of resources for care provision and refer to a set of nursing responsibilities or treatment measures accepted by clinical agreement and nurses' cooperation and are important for patients in order to reach their intended outcomes. This phrase is normally used when a nurse accepts that $s /$ he has not fulfilled a care and has postponed it to the next shift(12). Examples of this case include delay in feeding the patient (35). untimely admission for intensive care, delay in prescription of medications (36) and delay in diagnosis and treatment of serious complications (37).

\section{Antecedents}

According to the review of the literature, the antecedents of miss care could be classified into two categories:

\section{1) Organizational restrictors}

1-A) Human workforce for patient care: This deals with the number and characteristics of the staff (category, education level, job tenure, and work experience), which are associated with patients' demands for nursing care (5). Evidence has indicated that a qualified individual reduces miss care and affects the care outcomes (38).

\section{1-B) Available financial resources for helping the performance of the patients' required measures: This} refers to financial resources required for nursing care, such as medications, instruments, and equipment, whose accessibility affects the nurses' ability in care provision (5). Old facilities, lack of disposable goods, and lack of access to new and advanced instruments have been considered to be a part of system failure. These factors could increase the time required for instruments preparation and cause fatigue and burnout among nurses, consequently endangering nurses' safety. These, in turn, threaten patient safety and lead to patients' dissatisfaction and disruption of the treatment process (39).

1-C) Organizational support for nursing function: This includes first-line managers' support, sufficient resources, nurses' involvement in organizational decision-makings, and cooperative relations with physicians. Organizational support can affect the nurses' decision-making priorities. Thus, it is assumed to be effective in the care provided or not for patients (40).

\section{2) Process restrictors}

2-A) Nurse's internal values: The antecedents of miss nursing care that are effective in the process of nursing function are affected by nurses' internal processes and their consequences threaten patient safety (33). Nurses have internal values and beliefs about their role as a nurse, which affects their behaviors. The question is whether a nurse is not able to or does not want to carry out nursing cares at 
the standard level. Difference between a behavior and values can lead to the feeling of regret and guilt. Therefore, nurses' values, attitudes, and beliefs affect their intention to neglect or delay some parts of patient care (5). Moreover, lack of responsiveness, lack of attention to patient needs, lack of follow-up, and frequent negligence can result in ignorance of usual cares, which is influential in miss nursing care (39). Overall, nurses' decisions for fulfillment of particular care activities while eliminating or delaying other cares are mainly affected by their internal perceptions. Internal perceptions include team norms, decision-making styles, values, beliefs, habits, and attitudes based on which nurses understand their roles and responsibilities (41).

2-B) Nursing process: The five steps of the nursing process include evaluation, diagnosis, planning, execution, and evaluation. In each step, nurses can create an accurate structure for nursing care provision via performance of systematic and patient-oriented nursing measures. This informed, organized, and scientific approach requires thinking, knowledge, and judgement and can provide a common structure for nursing care (5). Miss care may occur in various known dimensions of nursing process; i.e., evaluation/diagnosis (evaluation of the risk of pressure ulcer), execution (perineal skin care), and evaluation (evaluation of skin integrity at the time of defecation) (42).

2-C) Inter-professional relations, relationships, and group work: Team work is an important component of work environments in healthcare. Effective group work is accompanied with positive outcomes for both staff and patients(8). In case a team lacks mutual trust, leadership, orientation, close relationships, and common mental models regarding task performance, it will have difficulty while encountering high workloads with the existing human resources (26). In fact, lack of coordination among healthcare team members exerts negative effects on the quality and continuation of care through weakening the nurses' roles in patient care (39). Team work refers to a set of knowledge, skills, and attitudes in the members, which helps them operate as a team. The main components of this concept include leadership, supervision on the situation, relationships, and supportive behavior (43).

\section{The outcomes of miss care were classified into two categories as follows:}

\section{a) Patient outcomes}

1-a) Patients' clinical outcomes: Various investigations have shown that patient falls, nosocomial infections, blood infection, urinary tract infection, pressure ulcer, medication errors, hospital-acquired pneumonia due to lack of oral hygiene, mortality, and readmission 30 days after discharge due to lack of patient training were associated with miss care $(9,21,25)$.

2-a) Patient satisfaction: Satisfaction has been referred to as a feeling of happiness and tranquility perceived by patients resulting from the nurses' emotional and intellectual acceptance (44). Nowadays, hospitals have found motivations for improving patients' satisfaction by incorporating patient satisfaction in payment programs and general reports. Furthermore, patient care experience is a fundamental qualitative index associated with nursing (45). Studies have demonstrated that patients with worse experiences were admitted in the hospitals where essential nursing cares were neglected (9). 
These included not giving medications at due times, not explaining the medications complications, lack of pain control, not providing information at the time of discharge, not talking to patients, and not training the patients and their families, which resulted in the patients' dissatisfaction. Yet, supporting the nurses' capabilities for completion of necessary cares could promote patient care experiences (45).

\section{b) Nurse outcomes}

Nurses are committed to provision of comprehensive patient care based on essential nursing values, including provision of special technical care and training (12). In case this is not possible due to the nurses' performance of non-nursing tasks such as answering the phone, transferring patients, and preparing the ward's required facilities and materials as well as lack of facilities, nurses will not be able to fulfill their responsibilities completely (35). Nurses' inability to provide high-quality patient care will in turn have a considerable impact on their job satisfaction and burnout (12). Job satisfaction points to achievement of success and satisfaction and consists of flexibility in work plan, independence, and educational opportunities (35). On the other hand, burnout has been described as a syndrome including emotional analysis, alienation, and reduction of personal success, which results in weakness in the quantity and quality of nursing care. It exerts negative effects, including fatigue, emotional fatigue, and shirking responsibilities, on most dimensions of individual, interpersonal, and organizational functions (46) ( Table 1).

Working definition: Based on the literature review, features, antecedents, and outcomes, the following working definition was proposed for the concept of miss care:

Miss nursing care is a healthcare error occurred due to a nurse's negligence in performance of one's duties. This phenomenon can occur due to organizational and process restrictors, which will have consequences for both the nurse and the patient.

\section{Table 1: The final analytical Theoretical}




\begin{tabular}{|c|c|c|}
\hline Categories & Theme & $\begin{array}{l}\text { Dimensions of } \\
\text { definition }\end{array}$ \\
\hline negligence errors & act of omission & The attributes \\
\hline Not performing the essential nursing care for patients & \multirow{2}{*}{$\begin{array}{l}\text { Breach of legal } \\
\text { duty of care }\end{array}$} & \\
\hline Delayed nursing care & & \\
\hline Human workforce for patient care & \multirow{3}{*}{$\begin{array}{l}\text { organizational } \\
\text { restrictors }\end{array}$} & \multirow{6}{*}{$\begin{array}{l}\text { The } \\
\text { antecedents }\end{array}$} \\
\hline $\begin{array}{l}\text { Available financial resources for helping the performance of } \\
\text { the patients' required measures }\end{array}$ & & \\
\hline Organizational support for nursing function & & \\
\hline Nurse's internal values & \multirow{3}{*}{$\begin{array}{l}\text { Process } \\
\text { restrictors }\end{array}$} & \\
\hline Nursing process & & \\
\hline Inter-professional relations, relationships, and group work & & \\
\hline Clinical outcomes & \multirow[t]{2}{*}{ Patient outcomes } & \multirow{4}{*}{$\begin{array}{l}\text { The } \\
\text { consequences }\end{array}$} \\
\hline Patient satisfaction & & \\
\hline Job satisfaction & \multirow[t]{2}{*}{ Nurse outcomes } & \\
\hline burnout & & \\
\hline
\end{tabular}

\section{Field work phase results}

The data were analyzed at the same time they were collected using inductive qualitative content analysis. In doing so, categories were extracted from the data and codes were extracted by reading the texts wordby-word for several times. At first, 65 codes were extracted and, they were integrated to eight categories and their relations were determined. After that, four main themes were extracted from the interviews' texts as follows: unmanaged care, silent care, background factors, and patient outcomes.

Attributes of miss care: Silent care and unmanaged care were two features of miss care in the field work(Table 2).

Silent care: The nurses under the current investigation stated that considering the needs and tasks description, they had to neglect some cares. In fact, regarding time, tasks, and patient conditions, nursing cares are prioritized and some cares are omitted due to lack of time. For instance, prescription of medications is more important than assisting the patients to walk and building relationships with them. Therefore, based on the clinical judgement, a nurse decides to ignore assisting the patients to walk, which may result in unwanted complications due to chemotherapy medications. 
Unmanaged care: This refers to a situation where patient needs are not well met due to lack of strategies for care provision, lack of team work, not using protocols and standards for care provision, and families' lack of cooperation in care provision.

\section{Antecedents:}

Background factors: The antecedents of miss care identified in the theoretical phase were observed and explored in the field work phase.

A.Organizational restrictors: Based on the participants' experiences, organizational restrictors, such as high workload, insufficient time, lack of on-arrival training, weak managerial support, inappropriate nurseto-patient ratio, and unavailability of facilities and equipment, increased the incidence of miss care. The participants maintained that in case these factors were eliminated, more high-quality care could be provided for patients. Other background factors for the incidence of miss care identified in the field work phase included lack of responsibility and patients' characteristics.

B.Nurses' lack of responsibility: There is a wide a range of responsibilities in nursing, including respect for clients, maintaining the dignity of patients, empathy, adherence to professional commitments, responsiveness, responsibility, work conscience, and justice in service provision (47). In the field work phase in the current study, the participants considered a nurse's responsibility as work conscience and lack of negligence, impatience, and inattention to dos and don'ts.

C.Patients' characteristics: Among the present study participants, some believed that a patient's or companion's different culture and age could cause difficulty in provision of nursing care. In fact, patients' or their companions' cultural differences may cause the nurse not to have a real perception of the patients, not to take measures for reduction of their problems, and become indifferent towards them. Families' lack of cooperation at the time of care provision was yet another reason mentioned by the participants. In this regard, patients' disability to express their care needs, companions' low education levels, and patients' inability to take care of themselves were among the challenges encountered by nurses at the time of care provision, which resulted in negligence of or delay in care provision.

Patient outcomes: This was one of the major outcomes of the field work phase and consisted of undesirable incidents and patient dissatisfaction(Table 2).

\section{Table 2.Examples of extracting of codes, sub categories, and categories from raw data}




\begin{tabular}{|c|c|c|c|}
\hline Meaning unit & Code & Subcategory & Category \\
\hline $\begin{array}{l}\text { Some things are likely to miss because the } \\
\text { patients go and back to the ward a lot and we } \\
\text { think that they know and we don't tell them. }\end{array}$ & $\begin{array}{l}\text { A realistic view } \\
\text { that miss care } \\
\text { is inevitable }\end{array}$ & $\begin{array}{l}\text { Conscious } \\
\text { change of care }\end{array}$ & \multirow[t]{2}{*}{ Silent care } \\
\hline $\begin{array}{l}\text { Based on my priorities, I don't play with my } \\
\text { patient. I say let me go and write nursing report. I } \\
\text { can't play with he anymore. For example, in the } \\
\text { morning shift I have to fill a box with } \\
\text { chemotherapic drugs and Every drug has its } \\
\text { own calculation , dilute and a Emptying the } \\
\text { drugs bottle. }\end{array}$ & Prioritize care & $\begin{array}{l}\text { Clinical } \\
\text { Judgment }\end{array}$ & \\
\hline $\begin{array}{l}\text { From the beginning of patient admission,we } \\
\text { have a series of special routines, such as } \\
\text { mouthwash which is written by a doctor. }\end{array}$ & $\begin{array}{l}\text { Routine and } \\
\text { non-use of } \\
\text { protocols and } \\
\text { standards }\end{array}$ & \multirow[t]{2}{*}{$\begin{array}{l}\text { No strategy for } \\
\text { reducing miss } \\
\text { care }\end{array}$} & \multirow[t]{2}{*}{$\begin{array}{l}\text { Unmanaged } \\
\text { care }\end{array}$} \\
\hline $\begin{array}{l}\text { Sometimes when we go to see the patient, she } \\
\text { scaredof us and crying.his/her. Mother says } \\
\text { youplease come back. I will give him/her } \\
\text { medicine. When you come back to the patient } \\
\text { again, she has not given the medicine yet. }\end{array}$ & $\begin{array}{l}\text { Lack of family } \\
\text { participationin } \\
\text { care }\end{array}$ & & \\
\hline $\begin{array}{l}\text { After the injection of drugs such as Viennese } \\
\text { Christian the patient must walk. Sometimes I } \\
\text { don't get the patient to walk.therfore I'll ask his } \\
\text { family to do thisand I emphasize that if you } \\
\text { don't your feet will cramp. This may or may not } \\
\text { be said at times. the first day that I want to give } \\
\text { the medicine I will train.but the next day which I } \\
\text { gana Prescribe the same drug, may not be } \\
\text { trained and I only say this drug is as same as } \\
\text { previous drug that I described for you yesterday. }\end{array}$ & $\begin{array}{l}\text { Sensory-motor } \\
\text { dysfunction }\end{array}$ & \multirow[t]{3}{*}{$\begin{array}{l}\text { Adverse } \\
\text { events }\end{array}$} & \multirow[t]{4}{*}{$\begin{array}{l}\text { Patient } \\
\text { Outcomes }\end{array}$} \\
\hline $\begin{array}{l}\text { We tell the visitor that you have to wash the } \\
\text { baby in warm water in order to doesn't get } \\
\text { annalfischer, wound and Constipation, because } \\
\text { of low immunity, it can cause infection. }\end{array}$ & Skin infection & & \\
\hline $\begin{array}{l}\text { Oral care is most important for oncology } \\
\text { patients, especially for children }\end{array}$ & Mouth fungus & & \\
\hline $\begin{array}{l}\text { The visitor says somebody(stafe) comes and } \\
\text { just give the medicine and go away. He/she } \\
\text { doesnt talk to my child, especially patients who } \\
\text { are hospitalized for a long time,say this. }\end{array}$ & $\begin{array}{l}\text { Lack of } \\
\text { communication }\end{array}$ & $\begin{array}{l}\text { Patient } \\
\text { dissatisfaction }\end{array}$ & \\
\hline
\end{tabular}

Undesirable incidents and patient dissatisfaction: The participants pointed to the undesirable incidents, which could result from the negligence of such cares as training the patients and their families, oral hygiene, and assisting the patients to walk after consuming vincristine. Experiences of participants also 
indicated that the incidence of these undesirable events as well as not building relationships with patients and their families could cause dissatisfaction among patients.

\section{The final analytical phase}

In this phase, the results of field work and theoretical phases were compared and integrated in order to produce a definition for miss care that will be supported by both the existing texts and the nurses. In so doing, all data were gathered in order to determine their content meanings. Then, use was made of a type of deductive analysis in which new experimental data were continuously compared to the primary definition of the concept. The new information could be employed for confirmation or revision of the hidden theoretical ideas in the operational definition. In fact, the data obtained from the interviews led to better recognition and insight towards the nature of the concept (48).

During the data collection process, simultaneous analysis and comparison were carried out. In so doing, the researcher went back and explored the details of the task by focusing on the initial theoretical findings. Further details have been presented in Table 3.

\section{The final definition of miss care}

Miss care is a healthcare error as a kind of negligence in which the nurse provides unmanaged patient care due to the adversity of organizational and process background factors, which results in the negligence of essential cares and leads to consequences for both the patient and the nurse.

In this stage, the results obtained in the theoretical and field work phases were integrated. Accordingly, the concept of miss care obtained in the theoretical analysis was redefined based on the insight gained through experimental observations. Analysis of the data obtained through the literature review and field work revealed four features for the concept of miss care as follows: unmanaged care, and silent care, healthcare error, negligence (Table 3).

Table 3.Comparison of the dimensions of miss care in the literature review to the features expressed in the participants' experiences. 


\begin{tabular}{|c|c|c|c|}
\hline Dimensions & $\begin{array}{l}\text { Results of } \\
\text { literature }\end{array}$ & $\begin{array}{l}\text { Results of participants' } \\
\text { experiences }\end{array}$ & Final results \\
\hline \multirow[t]{2}{*}{ Features } & Act of omission & Silent care & $\begin{array}{l}\text { Healthcare error as a kind of } \\
\text { negligence }\end{array}$ \\
\hline & $\begin{array}{l}\text { Breach of legal } \\
\text { dut of care }\end{array}$ & Unmanaged care & Unmanaged patient care \\
\hline \multirow[t]{2}{*}{ Antecedents } & $\begin{array}{l}\text { Process } \\
\text { restrictors }\end{array}$ & Background factors & $\begin{array}{l}\text { Organizational and process } \\
\text { background factors }\end{array}$ \\
\hline & $\begin{array}{l}\text { Organizational } \\
\text { restrictors }\end{array}$ & & \\
\hline \multirow[t]{2}{*}{ consequences } & Patient outcomes & Patient outcome & Healths'Outcomes \\
\hline & Nurse outcomes & & \\
\hline
\end{tabular}

All subcategories related to the theoretical and field work phases were also integrated in the final analysis. Comparison of the antecedents of miss care in the theoretical and field work phases indicated that the antecedents mentioned in the texts were more focused on financial and human resources as well as relationships, which were in agreement with the antecedents of background factors such as organizational restrictors, nurses' lack of responsibility, and patients' characteristics, which were obtained in the field work phase. Besides, consequences related to patients and nurses were two main outcomes in the theoretical phase, which were in line with patient-nurse consequences revealed in the field work phase.

\section{Discussion}

The present study aimed to clarify the concept of miss care via the concept analysis method using the hybrid approach. The results demonstrated novel perspectives regarding the concept of miss care. Accordingly, miss care can be regarded as a leading index in investigation of the function of organizational quality programs so as to promote the quality of nursing services and improve patients' conditions.Review of the literature indicated that the concept of miss care is an act of omission $(7,8,33)$. which occurs as a result of nursing staff's non-adherence to the standard elements of nursing care. World Health Organization (WHO) has defined error as not completing a planned action or application of an incorrect plan (49). In the field of patient safety, two types of errors have been mentioned as follows: acts of commission (e.g., marking the wrong eye for surgery) and acts of omission (e.g., not moving the patient). Miss nursing care is a form of acts of omission. These errors are easily neglected in comparison to those occurred due to carelessness and may lead to undesirable outcomes among patients, including dissatisfaction, sideeffects, mortality, and re-hospitalization (7). 
In the field work phase in the present study, miss care was defined as unmanaged care and silent care. Some features obtained in the field work phase were supported by the literature, as well. For instance, DehghanNiri disclosed that silent care resulted from systemic and managerial obstacles, which caused nurses to neglect cares and consider priorities in care provision. The results also showed that these priorities were determined based on the system's expectations, physicians' orders, and nurses' roles in the system (39). Another study indicated that miss care as a care process could be placed in the structureprocess-outcomes framework. Accordingly, organizational structure could affect the care process, revealing the mutual relationship between service providers and patients all through the care provision process. Then, this process could impact the care outcomes. In case this process is not managed well, it may result in the incidence of miss care (50). Hence, by providing care on the basis of nursing process, nurses can create a precise structure for nursing care provision and reduction of miss care (5). Yet, nurses' attempts alone are not sufficient and healthcare organizations have to provide the ground for patient care provision by creating motivation, provision of a supportive environment, and provision of financial and human resources (50).

The present study findings indicated that miss nursing care could affect safety, satisfaction, and length of hospital stay among patients and motivation, job satisfaction, absence, and request for ward change among nurses. In the same vein, Kalisch stated that the nurses' supportive capabilities for completion of patient cares could improve their care experiences and satisfaction (17). In another research, Kalisch reported that the nurses who experienced lower miss cares were more satisfied with their occupation (45). Yet, provision of high-quality care services needs some prerequisites. In case these prerequisites are not provided, miss nursing care may occur in the care environment (5). In this context, organizational and process restrictors were among the themes found in the present investigation. In this regard, some studies $(5,10)$. have revealed the lack of personnel as the main reason for miss care. For instance, inappropriate substitution of nurses at the time of absence or shift leave increased workload. Furthermore, organizational policies including employment of non-qualified personnel (such as nursing students) and execution of obligatory overtime in consecutive shifts due to failure or delay in service provision could lead to miss care (10).Moreover, availability of financial resources including medications and required instruments and equipment could affect the nurses' capability for care provision (5). Miss nursing care is not only a clinical process, but it is also an ethical decisionmaking process. Therefore, researchers investigated missed nursing care from the ethical viewpoint. They came to the conclusion that in addition to its negative consequences for patients (e.g., falling out of bed and pressure ulcer), miss nursing care could lead to role conflicts and ethical dilemmas among nurses (51).

Indeed, Srulovici et al. disclosed that nurses' responsibility played a far more important role in miss care compared to workload. Responsibility is a basic value associated with an individual's personal and professional identities, which has its roots in one's nurture, social and economic status, cultural background, professional socialization, and professional experiences(52). Nurses' responsibility can increase job motivation and guide them to decrease miss nursing care by the ethical standards obtained through individual and professional promotion irrespective of lack of resources (51). 


\section{Conclusion}

It seems that the result of this study somewhat assisted in clearing the concept of missed nursing care. By identifying the facilitating and preventive factors, and the concept of miss care, nursing managers and instructors will be able to design and run their management and educational activities based on scientific findings which could provide the necessary conditions for learning and proper implementation of nursing interventions.

\section{RELEVANCE TO CLINICAL PRACTICE}

Miss care affects nurses' performances and patients' outcomes as well as the whole system's managerial policies. Thus, nursing managers are faced with the problems associated with miss care directly or indirectly. By identification of the background factors of miss care, managers will be able to take measures for empowerment of human and financial resources and elimination of incompatibilities between the staff and workload. In this way, patients are continuously provided with the required cares, eventually preventing miss care and its impacts on care outcomes. Overall, clarification of the concept of miss care for nurses and provision of essential nursing services based on patient needs can reduce healthcare expenditures and increase motivation among nurses. Future studies are recommended to compare this concept to similar ones so as to identify clinical distinctions. Additionally, a questionnaire with appropriate psychometric properties is suggested to be designed in order to evaluate miss nu

\section{Declarations}

\section{Acknowledgement}

The authors would like to thank Dr. Kalisch for providing permission for using the miss car tool . They would also like to appreciate the authorities of the healthcare centers and the nurses who contributed their time and effort to this research in spite of their high workload.

\section{Conflict of Interest Statement}

All authors declare no financial, personal, or potential conflicts of interest

\section{Author's contributions}

Kh.HR was the study supervisor and contributed to all aspect of the study. R.Sh and SH.A and M.B collected data. R.Sh was the main investigator and provided the first draft. KH.Hr was the study advisor and contributed to the study design, critically reviewed the paper and provided the final draft. SH.A and M.B was the study advisor and contributed to the writing process, and the statistical advisor and contributed to data analysis. All authors read and approved of the final manuscript.

\section{Ethical approval}


The University Of Social Welfare and Rehabilitation Sciences Ethics Committee approved the study. All participants signed informed consent form.

\section{Funding}

This research was supported by University of Social Welfare and Rehabilitation Sciences(uswr) , Tehran, Iran.

Availability of data and materials: All available data can be obtained by contacting the corresponding author. All data requests should be submitted to the corresponding author for consideration. Access to anonymized data may be granted following a review

\section{References}

1. Kim K-J, Yoo MS, Seo EJ. Exploring the influence of nursing work environment and patient safety culture on missed nursing care in Korea. Asian nursing research. 2018;12(2):121-6.

2. Saqer TJ, AbuAlRub RF. Missed nursing care and its relationship with confidence in delegation among hospital nurses. Journal of clinical nursing. 2018;27(13-14):2887-95.

3. Kalisch BJ, Williams RA. Development and psychometric testing of a tool to measure missed nursing care. JONA: The Journal of Nursing Administration. 2009;39(5):211-9.

4. John ME, Mgbekem MA, Nsemo AD, Maxwell GI. Missed Nursing Care, Patient Outcomes and Care Outcomes in Selected Hospitals in Southern Nigeria. nursing.152:81.7.

5. Kalisch BJ, Landstrom GL, Hinshaw AS. Missed nursing care: a concept analysis. Journal of advanced nursing. 2009;65(7):1509-17.

6. Bagnasco A, Timmins F, de Vries JMA, Aleo G, Zanini M, Catania G, et al. Understanding and addressing missed care in clinical placements - Implications for nursing students and nurse educators. Nurse Education Today. 2017;56:1-5.

7. Moreno-Monsiváis MG, Moreno-Rodríguez C, Interial-Guzmán MG. Missed nursing care in hospitalized patients. Aquichan. 2015;15(3):318-28.

8. Bragadóttir H, Kalisch BJ, Tryggvadóttir GB. Correlates and predictors of missed nursing care in hospitals. Journal of clinical nursing. 2017;26(11-12):1524-34.

9. Recio-Saucedo A, Dall'Ora C, Maruotti A, Ball J, Briggs J, Meredith P, et al. What impact does nursing care left undone have on patient outcomes? Review of the literature. J Clin Nurs. 2018;27(1112):2248-59.

10. Dehghan-Nayeri N, Shali M, Navabi N, Ghaffari F. Perspectives of oncology unit nurse managers on missed nursing care: A Qualitative study. Asia-Pacific journal of oncology nursing. 2018;5(3):327.

11. Reason J. How necessary steps in a task get omitted: revising old ideas to combat a persistent problem. Cogn Technol. 1998;3:24-32. 
12. Marven AC. Missed nursing care-a nurse's perspective: an exploratory study into the who, what and why of missed care. 2016.

13. Lake ET, de Cordova PB, Barton S, Singh S, Agosto PD, Ely B, et al. Missed nursing care in pediatrics. Hospital pediatrics. 2017;7(7):378-84.

14. Taghinejad H, Suhrabi Z, Kikhavani S. Concept analysis of autonomy in nursing: A review Study. 2013.

15. Al M. Theoretical nursing:Development and progress: Lippincott Williams \& Wikins; 2007.

16. Bruyneel L, Li B, Ausserhofer D, Lesaffre E, Dumitrescu I, Smith HL, et al. Organization of Hospital Nursing, Provision of Nursing Care, and Patient Experiences With Care in Europe. Med Care Res Rev. 2015;72(6):643-64.

17. Kalisch B, Tschannen D, Lee H. Does missed nursing care predict job satisfaction? Journal of Healthcare Management. 2011;56(2):117-34.

18. Bahramnezhad F, Cheraghi MA, Salsali M, Asgari P, Fomani FK, Sanjari M, et al. Futile care; concept analysis based on a hybrid model. Global journal of health science. 2014;6(5):301.

19. Jasemi M, Valizadeh L, Zamanzadeh V, Keogh B. A concept analysis of holistic care by hybrid model. Indian journal of palliative care. 2017;23(1):71.

20. Walker LO AK. Strategies for theory construction in nursing.2005.

21. Kalisch BJ. Missed nursing care: a qualitative study. Journal of nursing care quality. 2006;21(4):30613.

22. Verrall C, Abery E, Harvey C, Henderson J, Willis E, Hamilton P, et al. Nurses and midwives perceptions of missed nursing care-A South Australian study. Collegian. 2015;22(4):413-20.

23. Winsett RP, Rottet K, Schmitt A, Wathen E, Wilson D, Group MNCC. Medical surgical nurses describe missed nursing care tasks-Evaluating our work environment. Applied Nursing Research. 2016;32:128-33.

24. Schubert M, Glass TR, Clarke SP, Aiken LH, Schaffert-Witvliet B, Sloane DM, et al. Rationing of nursing care and its relationship to patient outcomes: the Swiss extension of the International Hospital Outcomes Study. Int J Qual Health Care. 2008;20(4):227-37.

25. Papastavrou E, Andreou P, Efstathiou G. Rationing of nursing care and nurse-patient outcomes: a systematic review of quantitative studies. Int J Health Plann Manage. 2014;29(1):3-25.

26. Zúñiga F, Ausserhofer D, Hamers JPH, Engberg S, Simon M, Schwendimann R. The relationship of staffing and work environment with implicit rationing of nursing care in Swiss nursing homes - A cross-sectional study. International Journal of Nursing Studies. 2015;52(9):1463-74.

27. Sochalski J. Is more better? The relationship between nurse staffing and the quality of nursing care in hospitals. Medical care. 2004:II67-II73.

28. Blackman I, Henderson J, Willis E, Hamilton P, Toffoli L, Verrall C, et al. Factors influencing why nursing care is missed. Journal of clinical nursing. 2015;24(1-2):47-56. 
29. Ball JE, Bruyneel L, Aiken LH, Sermeus W, Sloane DM, Rafferty AM, et al. Post-operative mortality, missed care and nurse staffing in nine countries: A cross-sectional study. International Journal of Nursing Studies. 2018;78:10-5.

30. Nelson ST, Flynn L. Relationship between missed care and urinary tract infections in nursing homes. Geriatric Nursing. 2015;36(2):126-30.

31. Tesoro M, Peyser DJ, Villarente F. A Retrospective Study of Non-Ventilator-Associated Hospital Acquired Pneumonia Incidence and Missed Opportunities for Nursing Care. J Nurs Adm. 2018;48(5):285-91.

32. Kalisch BJ, McLaughlin M, Dabney BW. Patient perceptions of missed nursing care. Jt Comm J Qual Patient Saf. 2012;38(4):161-7.

33. Kalisch B. Errors of omission: How missed nursing care imperils patients. Journal of Nursing Regulation. 2016;7(3):64.

34. VanFosson CA, Jones TL, Yoder LH. Unfinished nursing care: An important performance measure for nursing care systems. Nurs Outlook. 2016;64(2):124-36.

35. Bekker M, Coetzee SK, Klopper HC, Ellis SM. Non-nursing tasks, nursing tasks left undone and job satisfaction among professional nurses in S outh A frican hospitals. Journal of nursing management. 2015;23(8):1115-25.

36. Warne S, Endacott R, Ryan H, Chamberlain W, Hendry J, Boulanger C, et al. Non-therapeutic omission of medications in acutely ill patients. Nursing in critical care. 2010;15(3):112-7.

37. Schubert M, Clarke SP, Aiken LH, De Geest S. Associations between rationing of nursing care and inpatient mortality in Swiss hospitals. International Journal for Quality in Health Care. 2012;24(3):230-8.

38. Valles JHH, Monsiváis MGM, Guzmán M, Interial G, Arreola LV. Nursing care missed in patients at risk of or having pressure ulcers. Revista latino-americana de enfermagem. 2016;24.

39. Dehghan-Nayeri N, Ghaffari F, Shali M. Exploring Iranian nurses' experiences of missed nursing care: a qualitative study: a threat to patient and nurses' health. Medical journal of the Islamic Republic of Iran. 2015;29:276.

40. Hessels AJ, Flynn L, Cimiotti JP, Cadmus E, Gershon RR. The impact of the nursing practice environment on missed nursing care. Clinical nursing studies. 2015;3(4):60.

41. Vryonides S, Papastavrou E, Charalambous A, Andreou P, Eleftheriou C, Merkouris A. Ethical climate and missed nursing care in cancer care units. Nursing ethics. 2018;25(6):707-23.

42. Friese $\mathrm{CR}$, Kalisch BJ, Lee KH. Patterns and correlates of missed nursing care in inpatient oncology units. Cancer nursing. 2013;36(6):E51.

43. Hwang J-I, Ahn J. Teamwork and clinical error reporting among nurses in Korean hospitals. Asian nursing research. 2015;9(1):14-20.

44. Ghods A, Mohammadi E, Vanaki Z, Kazemnejad A. Patients' satisfaction: nurses' perspective. Iranian Journal of Medical Ethics and History of Medicine. 2010;4(1):47-61. 
45. Lake ET, Germack HD, Viscardi MK. Missed nursing care is linked to patient satisfaction: a crosssectional study of US hospitals. BMJ quality \& safety. 2016;25(7):535-43.

46. Rafiee F, Oskouie F, Nikravesh M. Key factors in nurses' reaction to Burnout: A qualitative study. Razi Journal of Medical Sciences. 2007;13(53):83-94.

47. heydari a, vafaei sm, aghbati $n$. A concept analysis of Nursing responsibility. Journal of Clinical Nursing and Midwifery. 2016;4(4):80-92.

48. Schwartz-Barcott D, Patterson BJ, Lusardi P, Farmer BC. From practice to theory: tightening the link via three fieldwork strategies. Journal of Advanced Nursing. 2002;39(3):281-9.

49. Tschannen D, Kalisch BJ, Lee KH. Missed nursing care: the impact on intention to leave and turnover. Canadian Journal of Nursing Research Archive. 2010;42(4).

50. Park SH, Hanchett M, Ma C. Practice environment characteristics associated with missed nursing care. Journal of Nursing Scholarship. 2018;50(6):722-30.

51. Drach-Zahavy A, Srulovici E. The personality profile of the accountable nurse and missed nursing care. Journal of advanced nursing. 2019;75(2):368-79.

52. Srulovici E, Drach-Zahavy A. Nurses' personal and ward accountability and missed nursing care: A cross-sectional study. International journal of nursing studies. 2017;75:163-71.

\section{Figures}



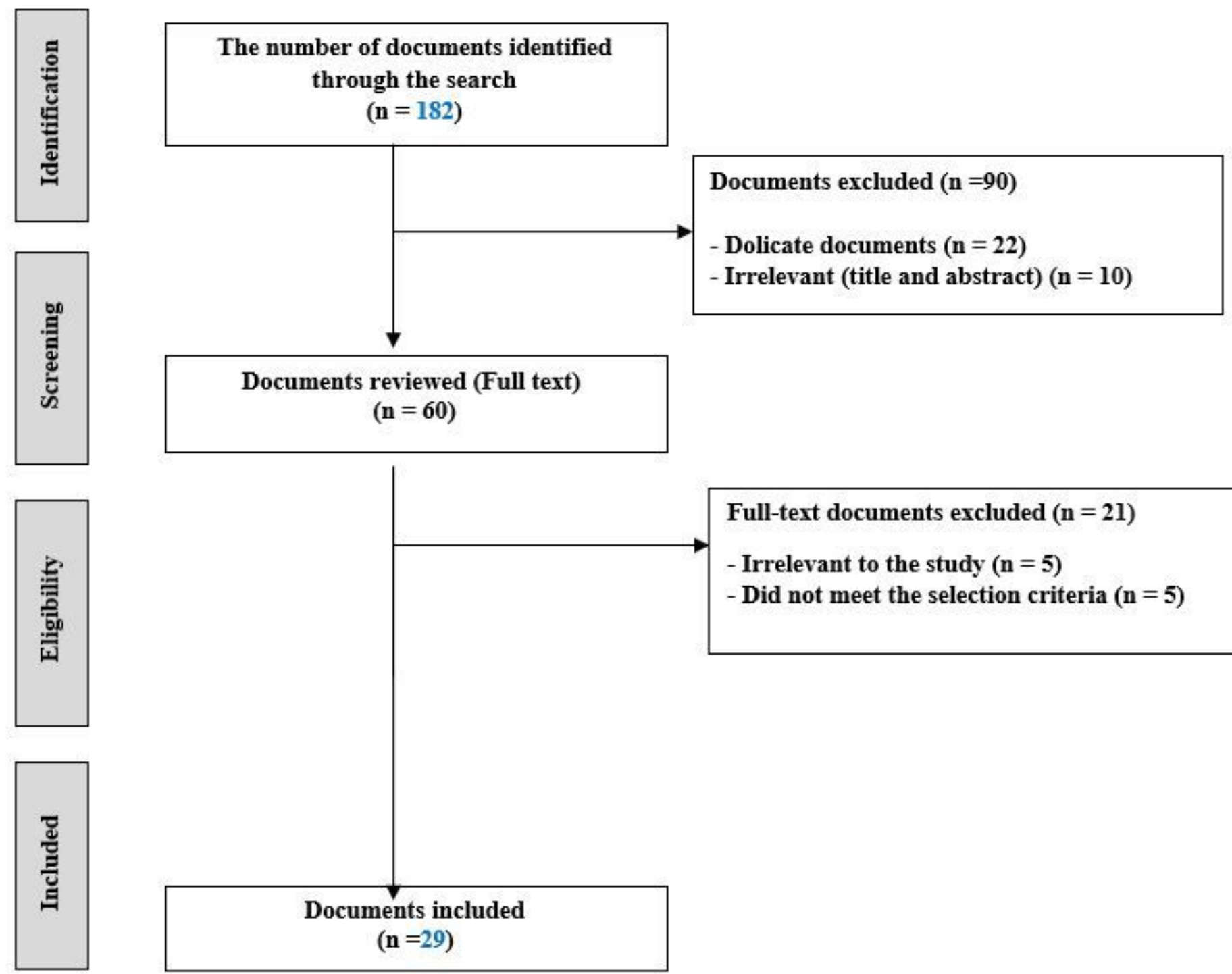

Full-text documents excluded $(n=21)$

- Irrelevant to the study $(n=5)$

- Did not meet the selection criteria $(n=5)$

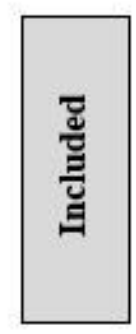

\section{Figure 1}

Search strategy

\section{Supplementary Files}

This is a list of supplementary files associated with this preprint. Click to download.

- questionnaire.docx 